\title{
Optimizing working conditions of air blast freezers in seafood processing factories
}

\author{
Minh Tuan Hoang ${ }^{\mathrm{a}}$, Xuan Vinh $\mathrm{Ha}^{\mathrm{b}}$, Chi Chinh Vo ${ }^{\text {cd }}$, Thanh Van Nguyen ${ }^{\mathrm{d}}$, Thi \\ Thuy Tien Nguyen ${ }^{\mathrm{e}}$
}

\author{
${ }^{a}$ Faculty of Thermal - Refrigeration and Construction, Hue Industrial College, Hue 530000, Vietnam \\ ${ }^{b}$ Faculty of Electronic, Hue Industrial College, Hue 530000, Vietnam \\ ${ }^{c}$ Department of Scientific Research and International Cooperation, Danang University of Science and Technology, Da Nang \\ 550000, Vietnam \\ ${ }^{d}$ Faculty of Thermal and Refrigeration Engineering, Danang University of Science and Technology, Da Nang 550000, Vietnam \\ ${ }^{e}$ Faculty of Engineering and Technology, College of Agriculture and Forestry, Hue University, Hue 530000, Vietnam
}

\begin{abstract}
At present, there are more than 633 seafood processing companies in Vietnam that consume $19.2 \%$ of the country's total industrial electrical power. The most popular freezers in these factories are air blast types. They are the most energy-consuming equipment, accounting for more than $50 \%$ of a company's total energy usage. Two key variables affecting the energy consumption of the freezers are freezing time and freezing temperature. In this study, a mathematical model was designed to determine the freezing time for food products and the refrigeration load of air blast freezers. It is presented as an objective function of total energy consumption for a given processing time. In addition, optimal freezing temperature, air velocity, and freezer efficiency were also determined. Our model can be used to operate air blast freezers with highest efficiency.
\end{abstract}

Keywords: Air blast freezer, frozen seafood, energy consumption, two-stage system of refrigeration

\section{Introduction}

Food safety and compliance with commercial contracts with customers from all over the world are of high priority to seafood exporters. However, competitive pricing of high-quality products is required for a company to increase its reputation and prestige. In Vietnam, exported seafood products are mainly frozen by air generated from freezers which were mostly imported in the 1980s. They consume more than $50 \%$ of total energy of the factories that utilize them. It was estimated that it takes about 68 to 188 kilogram of oil equivalents to freeze one ton of seafood products, accounting for $15-20 \%$ of its total production cost. Therefore, reduction of energy consumption is an attractive way for lowering costs and to enhance a company's competitiveness on the global market [1]. Currently, only a few methods are recommended to reduce energy cost, which includes optimizing intermediate pressure [2], analyzing airflow in freezers, or improving performance and improving design [3-7]. In addition, better control of the defrosting process in the cooling system was also reported to reduce energy cost [8]. However, no systematic study was performed to optimize energy reduction of air blast freezers. For those reasons, the present study was carried out to analyze the total heat load for air blast freezers using a two-stage refrigeration system at the Hue Industrial College, in Thua Thien Hue province, Vietnam. The total heat load summarizes the heat flow from many sources, including from the product during the freezing process, from cooling the packaging materials, from the fan motor, and from outside the cover structure, etc. In general, energy

\footnotetext{
${ }^{a}$ Manuscript received August 14, 2018; revised March 26, 2019.

Corresponding author. Tel.: +84905564874; E-mail address: hmtuan@hueic.edu.vn

doi: $10.12720 /$ sgce.8.3.354-360
} 
consumption always increases with decreasing temperature and increasing air velocity. Therefore, an optimal mode of operation is not obtained by considering each factor individually. By selecting the total freezing time based on product quality or practical factors, we discovered the optimal combination of velocity and air temperature for the processing time for squids. Thereby, an optimal operating mode for the squid freezing process was established.

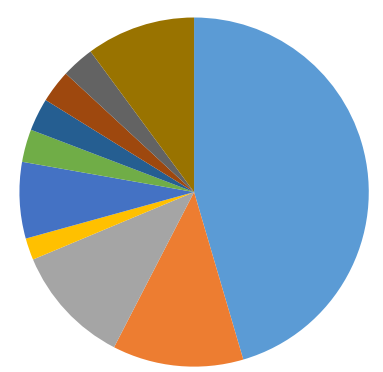

Freezing
Chilled water
Hot water
Others

$$
\begin{aligned}
& \text { Cold storage } \\
& \text { Air conditioning } \\
& \square \text { Water supply }
\end{aligned}
$$

$$
\begin{aligned}
& \text { Ice making } \\
& \text { Lighting } \\
& \text { Waste water treatment }
\end{aligned}
$$

Fig. 1. The share of energy consumption in catfish processing by end-use [1].

\section{Model Description}

The air blast freezer dimensions were $1.2 \mathrm{~m} \mathrm{x} 0.7 \mathrm{~m} \mathrm{x} 0.7 \mathrm{~m}$ (height $\mathrm{x}$ width $\mathrm{x}$ length), with $0.7 \mathrm{~m}$ of polystyrene insulation in the wall, roof and floor. To reach $-40^{\circ} \mathrm{C}$ of the air temperature in the freezer, a two-stage refrigeration system with the capacity of a $4 \mathrm{~kW}$ compressor, an indoor fan with a capacity of $0.12 \mathrm{~kW}$ and volumetric flow rate of $0.5 \mathrm{~m}^{3} / \mathrm{s}$ and pressure boost by a fan of $120 \mathrm{~Pa}$ was used. The air outdoor temperature was about $36^{\circ} \mathrm{C}$ during the summer.

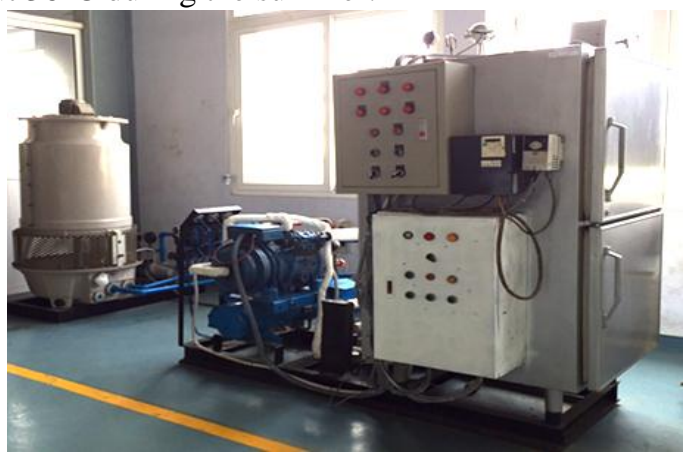

Fig. 2. Calculation model and experimental study

The total heat load was the sum of all the individual load components:

$$
Q_{t o t}=Q_{p}+Q_{p k}+Q_{f}+Q_{m d}+Q_{p e}+Q_{i}+Q_{s t}+Q_{d}
$$

where $Q_{p}$ was product load (W), $Q_{p k}$ was the packaging load (W), $Q_{f}$ was the fan load (W), $Q_{m d}$ was the lighting load (W), $Q_{p e}$ was people load (W), $Q_{i}$ was surface heat infiltration load $(\mathrm{W}), Q_{s t}$ was cooling of structures load (W) and $Q_{d}$ was load due to defrosting (W). 


\subsection{Freezer product heat load}

To calculate the total heat load for the freezing process during three stages of precooling, phase change, and sub-cooling to store temperature [4], we used:

$$
Q_{p}=\frac{M_{p} \cdot \Delta h_{f}}{t_{b}}
$$

And

$$
\Delta h_{f}=c_{l}\left(T_{i n}-T_{f}\right)+L+c_{s}\left(T_{f}-T_{a v}\right)
$$

where $M_{p}$ was the mass of product $(\mathrm{kg}), \Delta h_{f}$ was the total enthalpy change during freezing $(\mathrm{J} / \mathrm{kg}), t_{b}$ was the appropriate processing time (s), $c_{l}$ was the specific heat capacity of unfrozen material $(\mathrm{J} / \mathrm{kgK}), T_{i n}$ was the initial product temperature $\left({ }^{\circ} \mathrm{C}\right), T_{f}$ was the initial freezing temperature $\left({ }^{\circ} \mathrm{C}\right), L$ was the enthalpy change due to freezing $(\mathrm{J} / \mathrm{kg}), c_{s}$ was the specific heat capacity of frozen material $(\mathrm{J} / \mathrm{kgK})$ and $T_{a v}$ was final product temperature $\left({ }^{\circ} \mathrm{C}\right)$.

\subsection{Packaging heat load}

All packaging materials had very low moisture, and included plastics, metals and wood. Packaging heat load of freezing can be estimated [9]:

$$
Q_{p k}=\frac{M_{p k} c_{p k}\left(T_{i n}-T_{a}\right)}{t_{b}}
$$

where $M_{p k}$ was a mass of packaging material per batch $(\mathrm{kg}), c_{p k}$ was specific heat capacity of packaging $(\mathrm{J} / \mathrm{kgK})$ and $T_{a}$ was cooling medium temperature $\left({ }^{\circ} \mathrm{C}\right)$.

Table 1. Specific heat capacity of materials [9]

\begin{tabular}{ll}
\hline Materials & $c_{p k}(\mathrm{~J} / \mathrm{kgK})$ \\
\hline Plastics & 1600 \\
Steel & 500 \\
Aluminum & 850 \\
Wood & 2300 \\
Fiberite & 1400 \\
\hline
\end{tabular}

\subsection{Fan heat load}

The best energy use estimation of the fan was given by [10]:

$$
Q_{f}=\frac{Q \Delta P}{\eta_{f}}
$$

where $Q$ was the volumetric flow rate of air $\left(\mathrm{m}^{3} / \mathrm{s}\right), \Delta P$ was pressure drop in the facility (Pa) and $\eta_{f}$ was fan motor efficiency. Besides, the fan energy was proportional to the fan speed cubed [9]:

$$
Q_{f}(n)=Q_{f}(o)\left(\frac{v_{a}(n)}{v_{a}(o)}\right)^{3}
$$


where $Q_{f}(n)$ was fan energy at the new speed $(\mathrm{W}), Q_{f}(o)$ was the fan energy at old speed $(\mathrm{W}), v_{a}(n)$ was new air velocity $(\mathrm{m} / \mathrm{s})$ and $v_{a}(o)$ was old air velocity.

\subsection{Surface infiltration heat load}

The surface infiltration heat load depends on the insulation materials and construction of the walls, roof, floor and door of the refrigerated space, the wind conditions inside or outside, the surface area, and the temperature difference between the air inside the refrigerated space and the ambient air. The rate of heat infiltration can be calculated using [11]:

$$
Q_{i}=U A\left(T_{a m}-T_{a}\right)
$$

Where $U$ was the overall heat transfer coefficient $\left(\mathrm{W} / \mathrm{m}^{2} \mathrm{~K}\right), A$ was the wall area $\left(\mathrm{m}^{2}\right), T_{a m}$ was the ambient temperature $\left({ }^{\circ} \mathrm{C}\right)$ and $T_{a}$ was the inside temperature $\left({ }^{\circ} \mathrm{C}\right)$.

$$
U=\frac{1}{\frac{1}{h_{o}}+\sum \frac{x_{i}}{k_{i} E}+\frac{1}{h_{i}}}
$$

where $h_{o}$ was the convective heat transfer coefficient at the outer surface $\left(\mathrm{W} / \mathrm{m}^{2} \mathrm{~K}\right), x_{i}$ was the thickness of $\mathrm{i}^{\text {th }}$ layer in the wall $(\mathrm{m}), k_{i}$ was the thermal conductivity of $\mathrm{i}^{\text {th }}$ layer in the wall $(\mathrm{W} / \mathrm{mK}), E$ was the insulation effectiveness factor and $h_{i}$ was the convective heat transfer coefficient at the inner surface $\left(\mathrm{W} / \mathrm{m}^{2} \mathrm{~K}\right)$. For low air velocity $<0,4 \mathrm{~m} / \mathrm{s}$, we set $h_{o}$ and $h_{i}$ to about $7 \mathrm{~W} / \mathrm{m}^{2} \mathrm{~K}$. Otherwise, we used [9]:

$$
h=7,3 v_{a}^{0.8}
$$

where $v_{a}$ was air velocity over the surface $(\mathrm{m} / \mathrm{s})$.

Table 2 . Thermal conductivity values of materials [9]

\begin{tabular}{|c|c|c|c|c|c|c|c|}
\hline \multirow{3}{*}{ Room size } & \multicolumn{7}{|c|}{ Insulant type and age } \\
\hline & \multicolumn{2}{|c|}{ Sandwich panel } & \multicolumn{2}{|c|}{ Spray polyurethane } & \multicolumn{3}{|c|}{ Other insulants } \\
\hline & $>10$ years & new & $>10$ years & new & >30years & $>10$ years & new \\
\hline$<100 \mathrm{~m}^{3}$ & 2.6 & 1.8 & 2.3 & 1.6 & $3-6$ & 2.5 & 2.0 \\
\hline $100-500 \mathrm{~m}^{3}$ & 2.4 & 1.5 & 2.0 & 1.4 & $3-6$ & 2.5 & 1.8 \\
\hline $500-5000 \mathrm{~m}^{3}$ & 2.2 & 1.3 & 1.9 & 1.2 & $2-6$ & 2.0 & 1.5 \\
\hline$>5000 \mathrm{~m}^{3}$ & 2.0 & 1.2 & 1.8 & 1.2 & $2-6$ & 1.8 & 1.4 \\
\hline
\end{tabular}

\begin{tabular}{ll}
\hline Materials & $k_{i}(\mathrm{~W} / \mathrm{mK})$ \\
\hline Fiberglass & $0.040-0.050$ \\
Corkboard & $0.035-0.040$ \\
Polyurethane foam board & $0.022-0.030$ \\
Polystyrene foam board & $0.026-0.034$ \\
\hline
\end{tabular}

Table 3. Insulation effectiveness factor [9] 


\subsection{Freezing time prediction}

The total freezing time was the sum of pre-cooling, phase change, and the tempering time.

Table 4. Freezing time prediction [12]

\begin{tabular}{ll}
\hline Stages & $\tau$ (s) \\
\hline Pre-cooling & $\tau_{1}=\frac{\delta \rho_{l} c_{l}}{\left(\frac{\delta}{k_{l}}+\frac{1}{h}\right)^{-1}} \ln \frac{t_{i}-t_{a}}{t_{f}-t_{a}}$ \\
Phase change & $\tau_{2}=\frac{\rho_{l} \varphi L}{\left(t_{f}-t_{a}\right)}\left(\frac{\delta^{2}}{2 k_{l}}+\frac{\delta}{h}\right)$ \\
Tempering & $\tau_{1}=\frac{\delta \rho_{s} c_{s}}{\left(\frac{\delta}{k_{s}}+\frac{1}{h}\right)^{-1}} \ln \frac{t_{f}-t_{a}}{t_{a v}-t_{a}}$
\end{tabular}

\subsection{Objective function}

The total energy consumption (E) may be a better objective function, determined from:

$$
E=P \tau
$$

Where $\mathrm{P}$ was the power used by the fan $\left(\mathrm{P}_{\mathrm{f}}\right)$ and the compressor $\left(\mathrm{P}_{\text {comp }}\right)(\mathrm{W})$ and $\tau$ was the time per freezing cycle which must be equal to or greater than the freezing time of the product (s), in which:

$$
P_{\text {comp }}=\frac{Q_{\text {tot }}}{C O P}
$$

Where COP was the coefficient of performance. Typical values for actual COP's were as follows [9]:

$$
C O P=\frac{273+T_{e}}{T_{c}-T_{e}}(1-\alpha x)^{n} \eta_{i}
$$

And

$$
x=0.00563\left(1+0.00149 T_{d}+0.00398 T_{s}\right)\left(T_{d}-T_{s}\right)
$$

in which:

$$
\eta_{i}=0.00476 R_{p}^{2}-0.09238 R_{p}+0.89810 \text { with } R_{p}=P_{d} / P_{s}
$$

where $T_{e}$ was the evaporation temperature $\left({ }^{\circ} \mathrm{C}\right), T_{c}$ was the condensation temperature $\left({ }^{\circ} \mathrm{C}\right), \alpha$ and $n$ were empirical constants, $\eta_{i}$ was the isentropic efficiency, $x$ was fractional vaporization during expansion from $T_{d}$ to $T_{s}$ and $R_{p}$ was pressure ratio [9], [13]. 


\section{Simulation Results}

From the result of section 2, we calculated the heat load for $10 \mathrm{~kg}$ of squids (Todarodes pacificus) based on their thermal properties. The freezing time for a standard quality product was 8000 seconds $\left(t_{b}=8000 \mathrm{~s}\right)$. Therefore, the total energy consumption can be calculated using the following objective function:

$$
E=\left\{0.12+\left[1.721+0.009375 v_{a}(n)^{3}+0.00396\left(36-T_{a}\right)\right] / C O P\right\} \frac{8000}{3600}
$$

Using a Matlab program to calculate E over a certain time period and by considering the relationship between cooling medium temperature and the air velocity, we obtained the result illustrated in Fig. 3. Using function of minE, we had $\mathrm{E}_{\min }=2.6738(\mathrm{kWh})$, with $\mathrm{T}_{\mathrm{a}}=-38^{\circ} \mathrm{C}$ and $v_{a}=1.521(\mathrm{~m} / \mathrm{s})$.

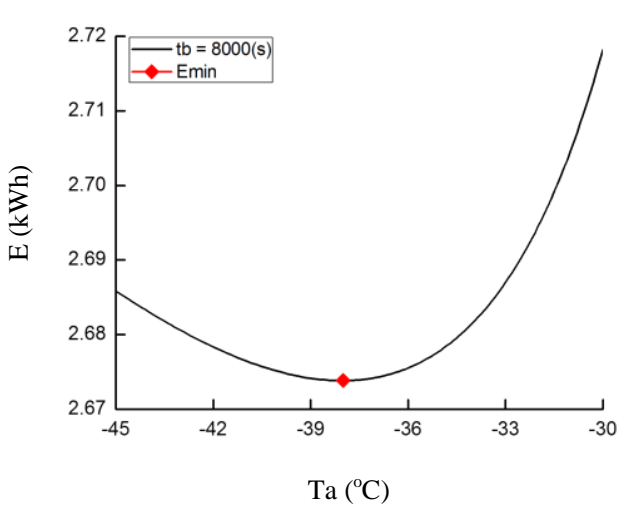

(a)

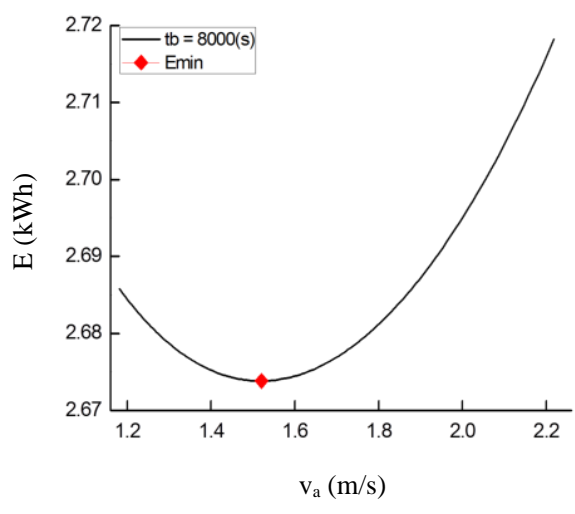

(b)

Fig. 3. Energy consumption versus cooling medium temperature (a) and air velocity for squid (b)

It can be observed in Fig. 4(a) that if the cooling medium temperature was to be decreased, the air velocity should be also decreased. And when the product's freezing time changes, while its quality was supposedly unchanged, the minimum energy curve was displayed as Fig. 4(b).

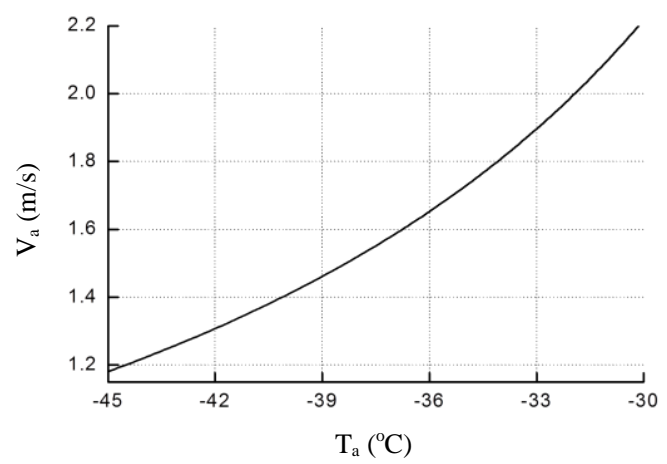

(a)

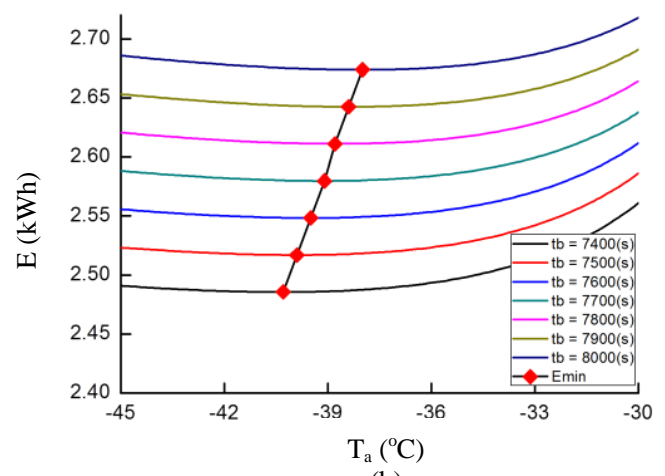

(b)

Fig. 4. Air velocity versus cooling medium temperature (a) and energy consumption versus freezing time (b)

\section{Conclusion}

This study provides a method for optimizing the operating mode of air blast freezers. The method was based on calculating the heat load and by building a target energy function for the system. The minimum energy consumption can theoretically be determined and predicted by the method presented here. This 
should help operators to operate the system optimally. Furthermore, competitiveness of the seafood processing company will be enhanced, since electricity consumption will be reduced. However, -precise operating procedures may vary because our working model can be affected by many factors such as cooling temperature, air velocity, product temperature, product shapes, as well as mechanical and thermodynamic features of the freezer.

\section{Acknowledgements}

We would like to express our sincere thanks to Associate Professor Ph.D. Pham Quang Tuan, School of Chemical Engineering and Industrial Chemistry, University of New South Wales, Sydney, Australia for his valuable support, guidance and knowledge sharing to publish this study.

This research has been partly funded by a scientific research in 2019, which is administered by Ministry of Industry and Trade of the Socialist Republic of Vietnam.

\section{References}

[1] Petersen PM. Review of food processing sector in Vietnam. Research report. Food processing industry - strategic sector study and subproject pipeline development for improving energy efficiency with integrated ozone and climate benefits, Niras, 2016.

[2] Jiang S, Wang S, Jin X, Yu Y. The role of optimum intermediate pressure in the design of two-stage vapour compression system: A further investigation. International Journal of Refrigeration, 2016; 70:57-70.

[3] Foster AM, Reinholdt LO, Brown T, Hammond E.C., Evans J.A. Reducing energy consumption in cold stores using a freely available mathematical model. Sustainable Cities and Society, 2016; 21:26-34.

[4] Lovatt SJ, Pham QT, Cleland AC and Loeffen MPF. Reducing energy consumption in cold stores using a freely available mathematical model. Sustainable Cities and Society, 2016; 21:26-34.

[5] Arnemann M. (July 2012). Energy efficiency of refrigeration systems. [Online]. Available: https://docs.lib.purdue.edu/cgi/viewcontent.cgi?article=2355\&context=iracc.

[6] Dempsey P, Bánal P. The art of air blast freezing: Design and efficiency considerations. Applied Thermal Engineering, 2012; 41: 71-83.

[7] Huan Z, Ma Y, He S. Airflow blockage and guide technology on energy saving for spiral quick-freezer. International Journal of Refrigeration, 2003; 26:644-651.

[8] Cai J. Control of refrigeration systems for trade-off between energy consumption and food quality loss. PhD thesis. Department of Electronic Systems, Aalborg University. Aalborg, Denmark; 2007.

[9] Cleland DJ, Cleland AC, White SD, Love RJ, Merts I, East A, et al. Cost-effective Refrigeration. 2nd ed. Palmerston: Massey University; 2014.

[10] Cleland DJ. Modelling of refrigeration processes. Presented at: $20101^{\text {st }}$ IIR International Cold Chain Conference, Cambridge UK.

[11] Yunus AC. Heat and Mass Transfer. 5th ed. Ohio: McGraw-Hill; 2015.

[12] Hoang M. T, Nguyen B, Vo C. C, Nguyen T. V. Calculation freezing time for brick shaped food by two nonsymmetric convection boundary. Thermal energy review, 2016; 127:18-23.

[13] Tsamos KM, Ge Y, Santosa I, Tassou S, Bianchi G, Mylona Z. Energy analysis of alternative $\mathrm{CO}_{2}$ refrigeration system configurations for retail food applications in moderate and warm climates. Energy Conversion and Management, 2017; 150:822-829. 